Canadian University Music Review

Canadian University Music Review

Revue de musique des universités canadiennes

--> Voir l'erratum concernant cet article

Reflections on the First Movement of Berg's Lyric Suite

Leonard Enns

Numéro 1, 1980

URI : https://id.erudit.org/iderudit/1013739ar

DOI : https://doi.org/10.7202/1013739ar

Aller au sommaire du numéro

Éditeur(s)

Canadian University Music Society / Société de musique des universités

canadiennes

ISSN

0710-0353 (imprimé)

2291-2436 (numérique)

Découvrir la revue

Citer cet article

Enns, L. (1980). Reflections on the First Movement of Berg's Lyric Suite.

Canadian University Music Review / Revue de musique des universités

canadiennes, (1), 147-155. https://doi.org/10.7202/1013739ar

All Rights Reserved (C Canadian University Music Society / Société de musique des universités canadiennes, 1980
Ce document est protégé par la loi sur le droit d'auteur. L'utilisation des services d'Érudit (y compris la reproduction) est assujettie à sa politique d'utilisation que vous pouvez consulter en ligne.

https://apropos.erudit.org/fr/usagers/politique-dutilisation/ 


\title{
REFLECTIONS ON THE FIRST MOVEMENT OF BERG'S LYRIC SUITE
}

\author{
Leonard Enns
}

The compositional technique displayed in Berg's Lyric Suite is at once superficially and profoundly related to the implications of the diatonic system. On a somewhat superficial level compositional aspects associated with the diatonic system pervade the work: the entire composition is cast in the form of a suite, individual movements display formal structures borrowed from diatonic music, ${ }^{1}$ traditional contrapuntal techniques are employed, ${ }^{2}$ and the vertical sonorities frequently bear a close resemblance to those of the tonal system. ${ }^{3}$

More significant implications of the diatonic system are to be seen in Berg's criteria of thematic equation. Just as composers of past centuries frequently depended more on rhythm and melodic contour than on exact pitch duplication to achieve thematic identity, ${ }^{4}$ so Berg uses similar rhythms and melodies, even though the intervallic content may be altered, to create relationships with previous material. This is clearly demonstrated in the analogous canonic sections of the first and second parts of the Allegretto (mm. 7-11 and 44-47) (See Perle 1972:62$63)$. In the first section the canonic theme comprises pitches 8-11 and $0-7$ of the row, while in the second section the canonic episode is recapitulated using pitches 1-11 of the retrograde inversion form (Ex. 1). The basic contour of the themes is similar, however, as is the rhythmic content.

This rhythmic content of the canonic themes is not original with the first statement, but is an almost direct restatement of the rhythmic format in which the row is first stated in measures 2-4 by the first violin (Ex. 2a). In fact, only a slight rhythmic difference obtains; the later canonic theme (Ex. 1, $\mathrm{mm} .44-46$ ), is in fact rhythmically identical to the original row 

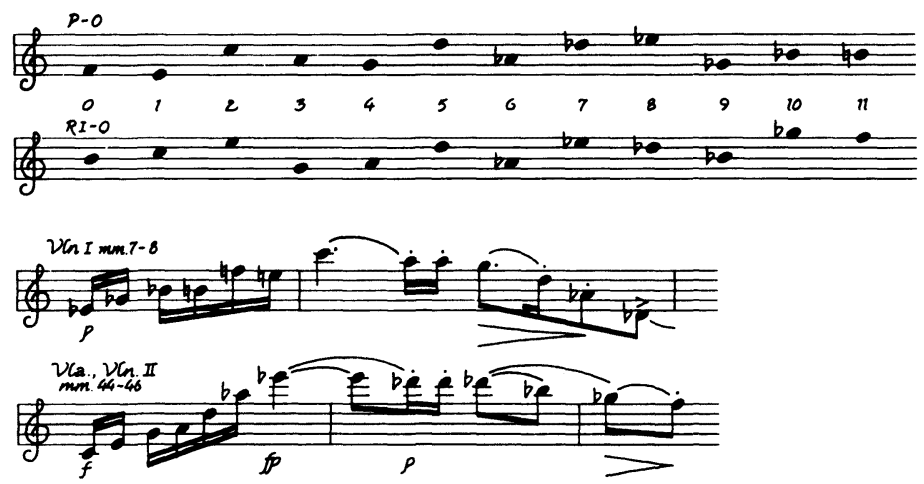

Example 1. Berg: Lyric Suite (1926), I: Allegretto giovale, mm. 7-8; 44-46.

exposition. Thus the canonic themes are themselves a direct development of the material in measures 2-4. That is, thematic equation is achieved with the original row statement through the retention of rhythmic content (and melodic contour), and development occurs due to the new relationship of the rhythm to pitch and interval content in each case. ${ }^{5}$

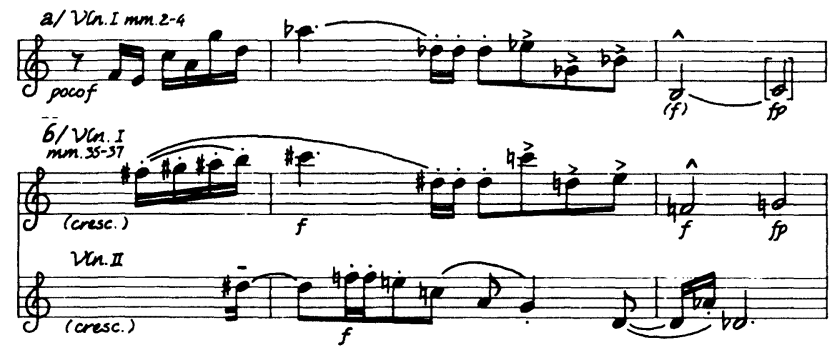

Example 2. Lyric Suite, I, mm. 2-4; 35-37.

The thematic importance of rhythm may also be seen in measures 36 and 37 (Ex. 2). These measures are structurally significant in that they articulate the midpoint of this binary movement, referring back to the opening material in the first violin, measures $2-4$. Here, however, the rhythmic and melodic contents of these opening measures are separated and a new kind of phase shift is made, in which the original rhythm and original melody are stated in another relationship and in two different instruments. The relatively high degree of audibility given to the rhythm by its placement in the uppermost voice again suggests that Berg considered rhythm to be of greater 
importance in establishing structural relationships than he did pitch. In fact, although all twelve pitches appear in measures 36 and 37, only the first eight pitches of the row appear in the original order in the second violin, diminishing still more the possibility of structural identification of these measures through pitch perception, and conversely strengthening the importance of the rhythmic element.

Another concept of the diatonic system which appears to be operative here is that of the establishment of a particular premise, the subsequent creation of tension or expectation by the digression from this premise, and the final relaxation of tension or fulfillment of expectation by returning to the original state. This is, of course, not a concept unique to the art of diatonic music; it amounts basically to the tautology that something is felt to be missing by the very fact that it is not present.

The concept may be seen at work in the first thirteen measures of the Lyric Suite. In the first measure the twelve notes of the chromatic scale are stated on the first three beats, and on the fourth beat all the "white notes" are recapitulated with the exception of $F$, the first pitch of the row to be exposed in the next measure (Ex. 3). (On a small scale, this situation already exemplifies the concept.)

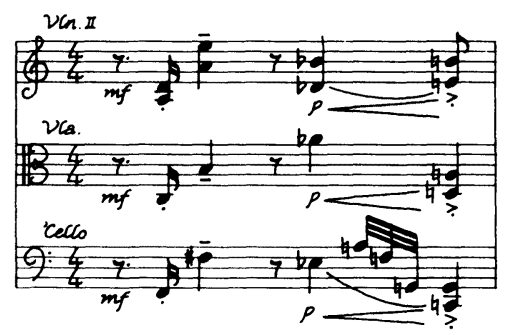

Example 3. Lyric Suite, I, m. 1.

The pitch which is particularly exposed on the fourth beat, due to its being the uppermost note in the sonority, is $\mathrm{B}$. This is a structurally important pitch, since conceptually it serves a dual role of completion: it is the final pitch of the row required for linear completion, and consequently it is the pitch which states the last element necessary for aggregate completion. The importance of this pitch is reinforced in the subsequent row statement in the first violin, where it receives the longest time value and is articulated by an accent. The note also receives 
gestural emphasis here, in that it is the lowest note of a descending line, and is preceded by three anticipatorily accented eighth notes (Ex. 2, mm. 3-4).

Having established the pitch B as an element of completion, Berg creates a certain compositional tension by avoiding any prominent use of the pitch again until the structural point at measure $13 .{ }^{6}$ When the B finally does return in the cello at the end of measure 12, it is given dynamic, textural, expressive, and durational prominence (Ex. 4).

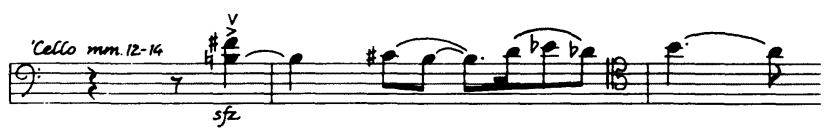

Example 4. Lyric Suite, I, mm. 12-14.

Durational prominence is given by the fact that it actually lasts for six beats (into the second beat of $\mathrm{m}$. 14) in elaborated form. An anticipatory rhythmic figure also precedes the $B$, as it had at the beginning of the movement. There, however, the figure comprised three accented eighth notes (Ex. 2), whereas here the anticipation is heightened through the diminution of the figure to two accented sixteenths and an eighth within the context of a ritardando (Vla., m. 12, not shown). The pitch gradually emerges as an exposed element at the end of the movement, being given a high degree of audibility by its appearance at both the upper and lower limits of the first violin phrase in measures 64-66, by its function as goal of that phrase, and by its appearance as the highest pitch in the final chord of the movement (Ex. 5). ${ }^{7}$

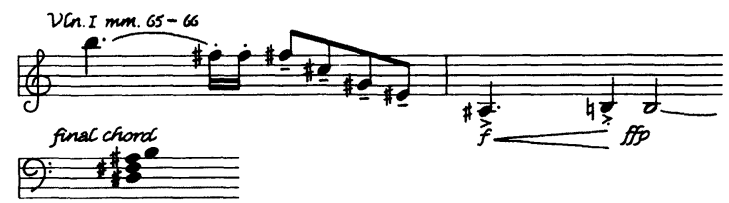

Example 5. Lyric Suite, I, mm. 65-66.

Possibly the most profound relationship between the compositional technique used in the Lyric Suite and the implications of the diatonic system is the fact that in both cases the precompositional character of the pitch material influences the formative aspects of the musical work, not only on the imme- 
diate level of melodic patterns and note tendencies, but also on broader structural levels. ${ }^{8}$ The most obvious aspect of the Allegretto row is the symmetry between its two hexachords, creating a tritonally related palindrome (Ex. 6). It is possible

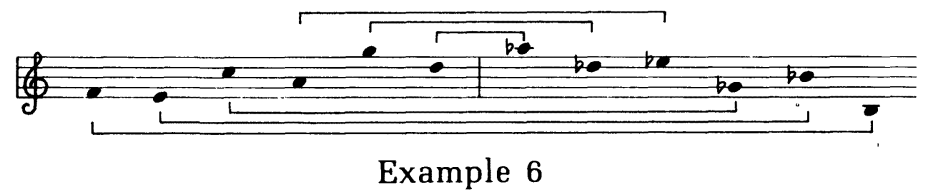

that this concept of reflection was operative in the composer's thinking at the basic level of row generation. The music of the first few measures strongly emphasizes the interval of the perfect fifth, through vertical and linear organization, and through the rhythmic structure of the first row statement. The first three chords of measure 1 actually reveal the raw material of the row and the technique used in its construction. A series of perfect fifths occurs in the first three beats, reading the first chord from the bottom up, reading the second chord in the reflected direction (from the top down), and reading the third chord from the inside out. ${ }^{9}$ Thus the second chord is a reflection of the first, and the third is a secondary kind of reflection, in which the inner interval of the fifth, D flat-A flat, is an image of the encompassing twelfth, E flat-B flat (Ex. 7). If two processes

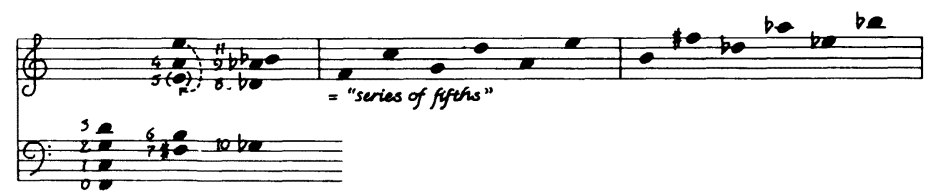

Example 7

of reflection similar to those revealed in the first measure are applied to its series of fifths in a linear rather than vertical manner, the row is obtained. The "first order" reflection simply involves reversing the order of the second six pitches (Ex. 8).

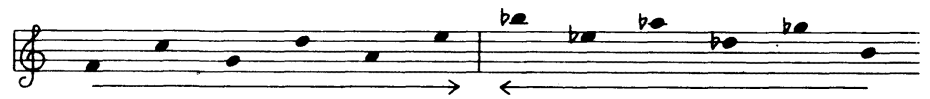

Example 8 
The "second order" reflection involves a similar reversal of the second trichord in the first hexachord, and an interlocking of the pitches of the first trichord and the reversed trichord (Ex. 9).

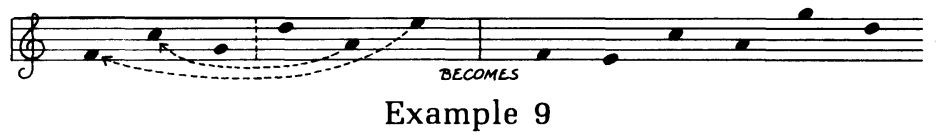

The same operation on the second hexachord yields the last half of the Allegretto row (Ex. 10).

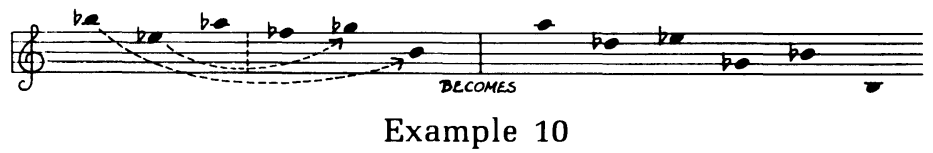

The concept of reflection, as implied in the structure of the row, is operative on several levels throughout the first movement and other sections of the Lyric Suite. ${ }^{10}$ A linear statement of the verticalized fifths of the introductory measure occurs at measures 34-36 in the cello, functioning now as both introduction to the recapitulation and as a link between the two parts of the movement, the first six pitches occurring at the end of the first half, and the reflective second six falling into the first measure of the recapitulation.

The relationship between measure 5 and its recapitulation in measure 38 reveals another implementation of the concept of reflection. Measure 38 is an exact retrograde (incorporating voice exchange) at the tritone of measure 5 (Ex. 11). In this case the rhythm is not used in retrograde, as it is in some other mirror relationships in this movement.

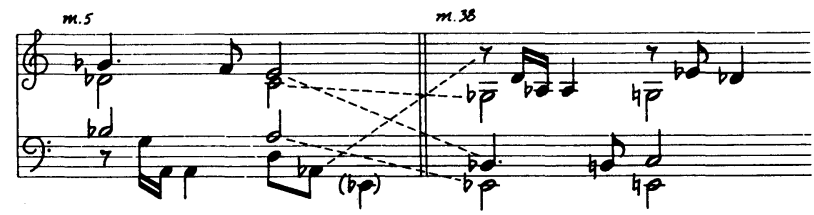

Example 11. Lyric Suite, I, mm. $5 \& 38$.

One such relationship occurs when the "row of fifths" which appears in retrograde in the cello, measures 7-9, is mirrored texturally, melodically, and rhythmically in measures 64-66, where it is contained mainly in the first violin part and is stated in (relative) melodic and almost exact rhythmic retro- 
grade (Ex. 12). A middle state of this total mirror occurs in measures 46-47, where the basic gesture is inverted, the sixteenth notes occur in the middle of the statement, and the "row" appears in a middle voice.
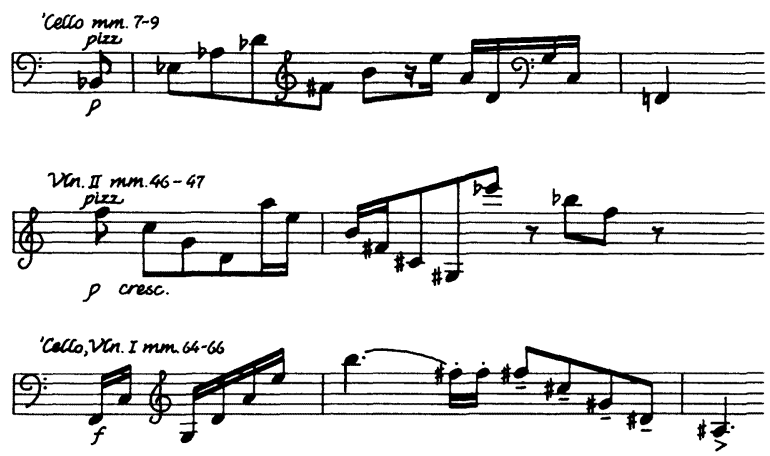

Example 12. Lyric Suite, I, mm. 7-9; 46-47; 64-66.

This discussion has suggested that some significant implications of the diatonic system are operative in the first movement of the Lyric Suite. The manner in which Berg's creative process was influenced by these implications is symptomatic of the aesthetic struggle in which the Viennese composers became engaged when they abandoned the traditional compositional road. 


\section{NOTES}

1. For example, the ABA structure of the third movement, or the binary structure of the first, which Stein calls a "sonata movement without development" in his introduction to the Philharmonia edition. For the sake of brevity, the derivative relationship between the inherent functions of the tonal system and historical forms such as binary, ternary, and sonata will be assumed without further discussion.

2. For example, the canonic writing in measures $7-11$ of the first movement.

3. See almost any measure in the first movement. Besides its relationship to the structure of the row itself, the resemblance of the vertical sonorities to tonal harmonies is largely a concomitant of Berg's apparent avoidance of prominent vertical semitonal or tritonal relationships in this movement. It is often possible to analyze the vertical structures as either seventh chords or triads with an added note. For example, measure 5, beat 1 : $G$ flat major; measure 3, beat 2: E flat minor with an added $A$ flat, and then $E$ flat minor seventh; measure 13, beat 1 : $F$ major seventh with an added $B$; measure 18 , beat 1 : $B$ diminished seventh, beat 2: F sharp diminished seventh, etc. (The two exceptional semitonal relationships in measure 13 have structural justification in that this measure articulates the second half of the first subject area.) When present, the added non-triadic element is usually in the principal $(\mathrm{H})$ or secondary voice $(N)$ thus making the melody-accompaniment distinction $\mathrm{a}^{\mathrm{t}}$ function of sonority as well.

It is to be understood that although names from the tonal vocabulary can be applied to many of the vertical structures in this work, these structures do not necessarily relate to each other in a functional-harmonic manner. The "chord naming" suggested here merely displays a superficial relationship which obtains between the Lyric Suite and the diatonic system. (It is interesting, however, that the bass of measure 1 outlines a quasi-I-V introductory gesture with its $\mathrm{F}$ and $\mathrm{C}$, after which the first violin states the row, beginning on $\mathrm{F}$ again. Such Procrustean analysis might even find the first chord of measure 4 to be a German sixth, leading to an altered V of $F$ on the third beat.)

4. For example, in a tonal fugal answer.

5. This situation is similar to the non-synchronized relationship of talea and color in some isorhythmic motets. In both measures 2-5 and measures 7- 8 the first violin states the row; in measure 2 the "talea" begins on the first pitch of the "color," while in measure 7 it begins on pitch 9. See Perle 1972:51 for a discussion of a similar situation in Schoenberg's Op. 23, No. 2, measures 18 and 19.

6. The lower three parts in measure 3 basically comprise the second hexachord of the row, with the notable omission of pitch 11(B). In measure 5 the same pitch is missing from the otherwise complete chromatic content; the situation is the same in measure 6 , which is a repetition of measure 5 with voice exchange and the use of $\mathrm{P}-0,4-7$ rather than $\mathrm{RI}-0,3-7$ in the second voice. The pitch does appear briefly in the canonic section, measures 7-11, by virtue of the fact that the entire row is used as the subject, but it is de-emphasized rhythmically and durationally, appearing on the second sixteenth of the beat and being given only a sixteenth value. See also the cello, measure 8 . 
7. Several levels of relationship obtain between this chord and the final chord of the first measure. The presence of $B$ in the uppermost voice in both chords provides a direct relationship. A constructional relationship exists in that the final chord may be derived from the measure 1 chord by taking its four outer pitches and collapsing them. The resultant chord, E G B C, becomes the final chord of the movement by the transposition of one semitone. The fact that these relationships are partially concomitants of the row structure itself does not necessarily decrease their architectonic significance.

8. The mode of a chant melody predetermines to some extent the types of melodic patterns used, the mode of the cantus firmus in a Renaissance motet is influential in the choice of cadences, and the polarities implied in the major and minor scales are reflected in such formalized logical extensions as the sonata form.

9. This series of fifths appears unaltered in the course of the movement as well: in retrograde in the cello, measures 7-9; in the original form in the cello, measures 34-36, and the second violin, measures 46-47; in retrograde in measures 61-63, beginning with the second violin and continuing in the cello (m. 63); and in its final statement beginning with the cello in measure 64 and continuing in the first violin to measure 66 (See Ex. 12). The stepwise arrangement of the twelve tones as they appear in measures 33-37, for example, is a corollary of the series of fifths, obtained by taking every second note within each six-note group. F C G D A E, for example, becomes F G A C D E, and an exchange of the trichords yields C D E F G A.

10. Simple functional inversion of parts is an obvious case in point. See, for example, the first violin, measures 28-29, and the recapitulation of this material in the cello, measures 58-61. A textural mirror occurs between the two - violin parts in measures $42-44$, in which the first violin has an intervallically expanding tremolo while the second violin has an intervallically contracting tremolo. The palindrome structures of the third movement are a straightforward example of reflection.

\section{REFERENCES}

PERLE, G.

1972: Serial Composition and Atonality. 3rd edition revised. Berkeley: University of California Press. 